\title{
Floating and fixed artificial habitats: effects of substratum motion on benthic communities in a coral reef environment
}

\author{
S. Perkol-Finkel ${ }^{1, *}$, G. Zilman ${ }^{2}$, I. Sella ${ }^{1}$, T. Miloh $^{2}$, Y. Benayahu ${ }^{1}$ \\ ${ }^{1}$ Department of Zoology, George S. Wise Faculty of Life Sciences, and ${ }^{2}$ Department of Fluid Mechanics, \\ The Faculty of Engineering, Tel Aviv University, PO Box 39040, Ramat Aviv 69978, Tel Aviv, Israel
}

\begin{abstract}
Despite the proliferation in coastal development world-wide little is known of the biological and ecological effects of man-made submerged habitats in coastal reefal environments. Such habitats, when able to move, offer unique environmental conditions, mainly in terms of hydrodynamic aspects. The current study tested whether floating habitats would develop unique communities in comparison to identical fixed ones, due to differences in current regime between the 2 types of habitat. We found significant differences in the hydrodynamic features associated with habitats of different motion capabilities, predominantly in mass-transfer rate, current velocity and shear stress. Floating installations had greater flow velocities and shear stress compared to fixed ones. We suggest that these hydrodynamic features determine the nature of the benthic communities on floating and fixed habitats, as the former revealed greater biomass and less chlorophyll content compared to the latter, while coral settlement was greater on the fixed installations, particularly near the seabed. The motion of floating artificial habitats increased the mass-transfer rate, as reflected by higher current velocities, and elevated the shear stress felt on their surfaces. These conditions encourage massive settlement of benthic macroinvertebrates and determine the community structure of floating artificial habitats in reefal environments.
\end{abstract}

KEY WORDS: Artificial reefs · Coastal development $\cdot$ Hydrodynamics $\cdot$ Current regime $\cdot$ Corals Benthic communities

\section{INTRODUCTION}

Most of the known and studied marine flora and fauna reside in coastal waters (Roberts \& Hawkins 1999). The same coastlines are also home to $>50 \%$ the world's human population, and this figure may reach as much as $75 \%$ by the year 2020 (IPCC 1994). This has led to a substantial increase in coastal development and usage, including the construction of various manmade submerged habitats like marinas, breakwaters, artificial islands, and floating bridges (Bellan \& BellanSantini 2001, Holloway \& Connell 2002). The study of urban marine environments as ecological habitats has been recently recognized as an important priority for ecologists (McDonnell \& Pickett 1990). However, despite the continuing proliferation of coastal urban habitats, little is known of their impact on the natural surroundings (Svane \& Petersen 2001, Wilding \& Sayer 2002).

Studies investigating man-made habitats in coastal zones have dealt mostly with the early developmental stages of fouling organisms, particularly on breakwaters and marinas (Glasby 1999, Chapman \& Bulleri 2003). Most studies were conducted in temperate waters; for example, the fouling communities of pontoons in Sydney harbor were compared to those of adjacent rocky habitats (e.g. Connell \& Glasby 1999, Connell 2000, Holloway \& Connell 2002). It was found that although the composition and structure of the artificial habitats had little influence on their community 
structure, their movement (i.e. when floating) greatly influenced developing fouling communities, due to differences in water flow between the moving and the fixed substrata (Glasby 2001). Most studies comparing coastal artificial and natural habitats found distinct differences in species abundance and distribution between the two, and, thus, coastal urban structures have been defined as novel habitats (Holloway \& Connell 2002, Chapman \& Bulleri 2003).

Chou \& Lim (1986) compared coral communities on concrete pillars to the adjacent natural surroundings in Singapore and found elevated species diversity and coral cover on the former. Perkol-Finkel \& Benayahu (2004) studied submerged metal and PVC nets in the northern Red Sea and demonstrated coral diversity and cover comparable to that of adjacent natural reefs, but with much higher soft coral diversity and cover on the artificial habitats compared to the natural ones. The community structure on urban submerged habitats thus appears to differ to that of adjacent natural surroundings, making the study of these habitats in tropical systems of great interest.

Although traditionally used for enhancing fish catches, artificial reefs nowadays are widely applied for various purposes such as aquaculture, rehabilitation of degraded reefs, conservation of biodiversity, and to test ecological theories (Baine 2001, Seaman 2002). Arguments for using artificial reefs for the study of development of benthic communities in marine urban environments can be found in the ease of manipulation of their spatial orientation, composition, complexity, heterogeneity and stability (e.g. Oren \& Benayahu 1997, Glasby \& Connell 2001, Holloway \& Connell 2002, Qiu et al. 2003). Other factors such as current regime, tidal and wind-driven circulation, sedimenttransport processes, temperature and salinity need to be evaluated in the surroundings of the artificial reef, as they might affect its developing community structure (Sheng 2000). For example, it was suggested that differences in epibiotic assemblages on pontoons and natural rocky reefs were mostly due to the presence of swash only on the former type, as well as to differences in the current regime (Glasby 2001, Holloway \& Connell 2002). Perkol-Finkel \& Benayahu (2004) suggested that differences between unplanned artificial reefs (i.e. metal and PVC nets) and adjacent natural reefs in the Red Sea were mainly due to differential current regimes. The motion of a movable substratum affects the surrounding water flow, which may, in turn, influence its species assemblage.

Current regime affects sediment load, oxygen and nutrient concentrations, food and nutrient supplies, etc. (Shimeta \& Jumars 1991, Baird \& Atkinson 1997 , Sebens et al. 1998) and plays a major role in determining the settlement and dispersal processes of marine larvae (Abelson \& Denny 1997, Eckman \& Duggins 1998, Fonseca 1999). Little is known about the hydrodynamic aspects that control settlement on submerged structures (Abelson et al. 1994). Modeling of larval settlement behavior and examination of their behavior under artificially induced current regimes in the laboratory have been performed for different fouling organisms (Gross et al. 1992, Abelson 1997, Qian et al. 2000), but it is difficult to extrapolate from these models to conditions in the field (Abelson \& Denny 1997). Flow can be measured with current meters (Kraines et al. 1998, Sebens et al. 1998), dye erosion (Wethey 1986, Boxshall 2000), or clod cards (Doty 1971, Thompson \& Glenn 1994). Nonetheless, there are only a few studies that have directly found a link between small-scale current regimes on artificial habitats and the features of their developing communities.

The current study aimed at linking hydrodynamic and biological aspects of artificial habitats by comparing the development of benthic communities on experimental artificial installations. We hypothesized that floating artificial habitats are likely to be inhabited by unique benthic communities, different from those of structurally identical fixed habitats. We tested for differences in biomass, chlorophyll content and coral recruitment between floating and fixed artificial installations, between different positions in the water column (i.e. seabed, mid water and near surface) and between vertical and horizontal orientations of the substratum. We used 2 types of artificial installations: floating, suspended in the water column and thus capable of both linear and angular motion, and fixed, attached to a firm substratum and therefore motionless. Specifically, the goals of the study were to compare the 2 types of installation by: (1) characterizing their current regime; (2) examining their developing benthic communities; and (3) determining the differential effects of substratum stability, orientation and position in the water column on the developing fouling assemblages.

\section{MATERIALS AND METHODS}

Study sites. The experimental arrays were deployed at 3 sites at the northern tip of the Gulf of Eilat, Red Sea (Fig. 1). There were 2 shallow sites, with bottom depths of $13 \mathrm{~m}$ : the underwater observatory (observatory) and the north oil jetty (north jetty), and 1 deeper site at $28 \mathrm{~m}$ : the south oil jetty (south jetty). At the observatory, fixed installations (see 'Experimental layout') were attached to a vertical metal mesh surrounding the structure using metal cables. Due to marine navigation restrictions in the area, floating installations were set ca. $50 \mathrm{~m}$ south of the observatory on a gravel- 


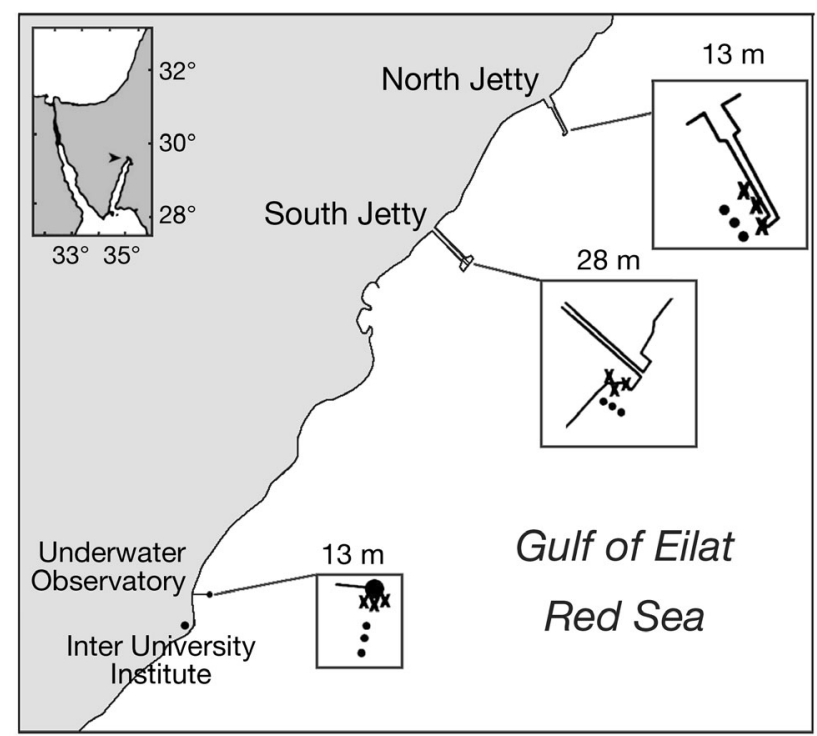

Fig. 1. Map of the study sites (observatory, north and south jetties) and position of the experimental layout ( $\mathbf{x}$ : fixed installations; $\bullet$ : floating installations)

covered slope near the Interuniversity Institute of Eilat (IUI). Fixed installations at the north and south jetties were attached by metal bands to the vertical supporting pillars of the jetties (Fig. 1). The floating installations were set on a sandy bottom, ca. $5 \mathrm{~m}$ away from the fixed ones. All installations were deployed during September 2002.

Experimental layout. The experimental layout consisted of artificial installations, each comprising 3 identical box-shaped modules. The modules were $60 \times 45 \times$ $45 \mathrm{~cm}$ in size and made of $8 \mathrm{~mm}$ galvanized metal mesh. To each module, 32 settlement plates $(11.5 \times 20$ $\times 1.5 \mathrm{~cm}$ ) made of recycled plastic (Aviv Recycling Industries) were attached using cable ties, half of which were positioned vertically and half horizontally; all were arranged in a step-like formation. Each settlement plate had a total surface area of $554.5 \mathrm{~cm}^{2}$, including both faces of the plate (Face A: facing out from the module; Face B: facing in) and its edges. The module was divided into upper and lower domains, perpendicular to each other. An experimental installation consisted of 2 to 3 modules (Fig. 2). The modules of each installation were suspended at 3 positions in relation to the water column: seabed (seabed), midwater (mid) and sea surface (surface), with a $5 \mathrm{~m}$ interval between them (Fig. 2A,B). Shallow installations were comprised of all 3 modules set at 12,6 and $1 \mathrm{~m}$ depths, respectively, while deep installations included only the lower 2 modules (seabed and mid), set at 27 and $21 \mathrm{~m}$, respectively. We constructed floating installations with movable modules and fixed installations with motionless ones. Modules of the floating installa-

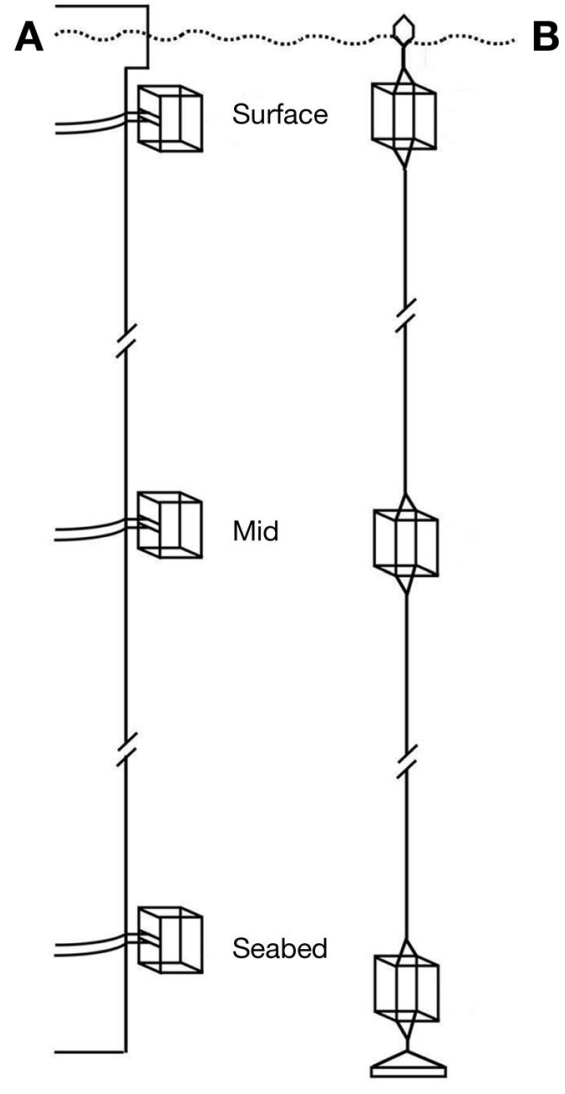

Fig. 2. Schematic illustrations of the fixed and floating installations. (A) Modules of a fixed installation attached to a firm substratum (jetty pole) using a metal band. (B) Floating installation held by a sinker to the seabed and suspended at the sea surface by a buoy; modules connected to each other by rope. Distance between modules ca. $5 \mathrm{~m}$

tions were aligned along a $10 \mathrm{~mm}$ thick plastic rope, held to the bottom by a $160 \mathrm{~kg}$ concrete sinker and floated by two $30 \mathrm{l}$ buoys (Fig. 2). This construction allowed each module independent movement, transition and rotation with 6 degrees of freedom: 3 linear velocities (longitudinal, transverse and vertical) and 3 angular velocities (longitudinal, horizontal and vertical), due to the effects of wind, current, wave motion and tide. Modules of the fixed installations were tightly attached to underwater metal nets or pillars, either directly or by a metal band (Fig. 2); 3 fixed and 3 floating installations were deployed at each site (Fig. 1).

Hydrodynamic analyses. Mass-transfer rate at floating and fixed installations: In order to measure the mass-transfer rate of water through the modules of the installations we used 'clod cards' (plaster cubes attached to PVC plates; see Doty 1971). This method converts loss of plaster from molds after exposure to water motion to mass-transfer rate of water with time. We used cone-shaped clods, with a dry weight of $25 \pm 0.5 \mathrm{~g}$ after $48 \mathrm{~h}$ at $60^{\circ} \mathrm{C}$, glued by marine cement 
to $5 \times 10 \times 0.3 \mathrm{~cm}$ PVC plates (see also Doty 1971). Each clod with its attached plate was weighed prior to exposure to seawater. They were then attached to the experimental settlement plates of each module using plastic clips. After $24 \mathrm{~h}$ of exposure at sea the clod cards were retrieved, dried for $48 \mathrm{~h}$ at $60^{\circ} \mathrm{C}$ and reweighed. Weight loss was calculated as the percentage of plaster lost from the initial value. Three experiments were run at each of the 3 study sites simultaneously, for all modules of both the fixed and floating installations. The first experiment (27 and 28 July 2003) tested the difference in weight loss between Faces A and B of the uppermost horizontal settlement plates. The second experiment (12 and 13 August 2003) tested the difference between vertical and horizontal plates, in which the clods were placed at the inner face (B) of both vertical and horizontal uppermost plates (see above). The third experiment (26 and 27 November 2003) tested the difference between the innermost part of the module and the uppermost part (Face B of the upper horizontal plate). In each experiment 6 clods were placed at each location, i.e. each plate face, orientation, or inner/upper part of the module $(2$ clods per module $\times 3$ modules per depth for each type of installation). Significance of the results was tested with factorial ANOVA (analysis of variance) tests using the STATISTICA program. The factors tested were treatment (floating, fixed), module (seabed, mid, surface) and location of the clods (for Expt 1: Face A/B; Expt 2: vertical/horizontal; Expt 3: in/up). All tests were done on $\arcsin \sqrt{\mathrm{X}}$-transformed data, and averaged values of the community features are presented with standard deviations (SD).

In order to convert the percentage loss of plaster to current velocity, we ran a calibration experiment in November 2003. Clod cards were placed in a tank of running seawater at the IUI (see Kiflawi \& Genin 1997) at velocities of $0,6,12$ and $18 \mathrm{~cm} \mathrm{~s}^{-1}$ for $24 \mathrm{~h}$ of exposure ( $\mathrm{n}=6$ clods for each velocity). Water temperature in the tank corresponded to the ambient seawater temperature from July through November 2003 (26 to $\left.27^{\circ} \mathrm{C}\right)$, as well as water salinity $(40.7 \mathrm{ppt})$. The correlation between velocity and percentage weight loss was tested using Pearson's correlation coefficient.

Movement frequency of floating installations: Numerous visual observations conducted by us revealed that the motion of the modules had a complex 3-dimensional character with 6 degrees of freedom. As a result, the vortical fluid motion inside the modules was too complex to be evaluated. We estimated certain representative parameters of the flow by observing and quantifying some of the general qualitative characteristics of the installations' motion (i.e. movement amplitude and frequency). The latter was done using digital video photography, whereby each module of a single floating installation at the north jetty was surveyed by a stationary video camera for $10 \mathrm{~min}$ (14 April 2003). A certain reference point for the module was chosen, and its time-dependent displacement in the fixed earth coordinate system was measured at $3 \mathrm{~s}$ intervals for 6 consecutive minutes. All distances measured on screen were normalized to actual distance (cm). As this measurement did not allow us to evaluate the full 6 degree of freedom motion of the modules, we also examined their rotation angles in addition to the noted horizontal displacement as a function of time $t$.

In order to calculate the frequency, amplitude and velocity of the modules' movement, we analyzed the time series $x(t)$ containing discrete $N(120)$ measurements $x_{n}\left(t_{n}\right)$ with resolution $t_{n+1}-t_{n}=3 \mathrm{~s}$ and a time period of $T_{p}=360 \mathrm{~s}$. The analysis showed that the modules undergo oscillatory motion around an equilibrium position such that:

$$
\bar{x}=\sum_{n=1}^{N} x_{n} / N
$$

We calculated the movement frequencies of the oscillatory motion of the floating installations using spectrograms of the time series. Denoting the displacement of the module as a function of time, $x(t)$, can be represented as a Fourier sum:

$$
x(t)=A_{0}+\sum_{q=1}^{N / 2} A_{q} \cos \left(\frac{2 \pi q t}{T_{p}}\right)+\sum_{q=1}^{[N / 2]-1} B_{q} \sin \left(\frac{2 \pi q t}{T_{p}}\right)
$$

The Fourier coefficients were calculated in a standard way (Bendat \& Piersol 1980). Having calculated the spectrograms, we were then able to find the spectral density of the oscillations, which characterizes the energy of oscillations in the range of certain frequencies. These results can be used for analysis of dynamic systems undergoing random oscillations.

In order to check the hypothesis that differences in larval settlement on fixed and floating habitats were due to the different shear stresses acting on a larva once attached to a rigid body (i.e. the settlement plates), we estimated the shear stress of the fixed and floating settlement plates. Due to the small size of planulae (ca. 1 to $3 \mathrm{~mm}$; Ben-David-Zaslow \& Benayahu 1998, Harii \& Kayanne 2002), it was assumed that the shear stress acting on its surface is close to that acting on the surface of the plates (moving or fixed). We used the Blasius viscous layer for calculating the shear stress on a fixed plate located in ambient steady flow, whereas for a floating plate oscillating in calm water the Stokes viscous layer was employed (Schlichting 1979). The shear stress $\tau_{0}$ on a fixed plate can be represented as:

$$
\tau_{0}=0.33 \sqrt{\mu \rho U^{3} / x}
$$

where $U$ is the ambient steady velocity, $\mu$ is water viscosity, $\rho$ is water density and $x$ is the distance from the 

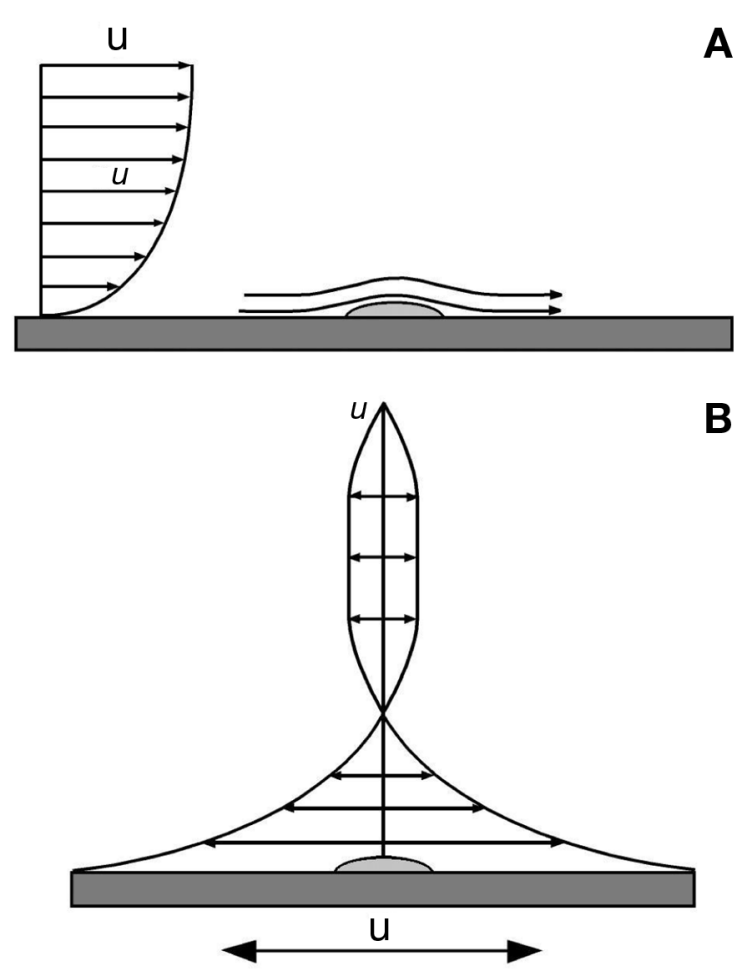

Fig. 3. Schematic illustration of the ambient flow $(U)$ acting on larvae attached to: (A) fixed and (B) floating settlement plates

leading edge of the plate. Therefore, a planula attached to a fixed plate will be subject to a constant shear stress $\tau_{0}$ (Fig. 3A). For calculating shear stress $\tau$ for a floating plate with amplitude $u_{0}$ and frequency $f$, we used the Stokes shear stress (Schlichting 1979) for an oscillatory laminar flow represented by:

$$
\tau_{t}=u_{0} \sqrt{\frac{\mu \rho \omega}{2}}(1+i) \exp (i \omega t)
$$

where $\omega=2 \pi f$ and $i^{2}=-1$. Therefore, as the velocity on the surface of a floating plate changes its value (Fig. 3B), a planula attached to the plate will be exposed to time-dependent shear stress $\tau_{1}$, which depends on the ambient flow velocity and on the frequency of the plate's motion.

In order to compare the shear stress on fixed and floating plates, we first had to calculate the spectrum of the shear stress on a floating plate. For random velocity of the plates' oscillations $u(t)$, the spectral density of the shear stress $S_{\tau}$ and the spectral density $S_{u}$ of the oscillatory velocity of the plate are related (Bendat \& Piersol 1980) such that:

$$
S_{\tau}=\left|(1+i) \sqrt{\frac{\mu \rho \omega}{2}}\right|^{2} S_{u}
$$

where the spectrum of velocities $S_{u}$ can be expressed through the spectrum of the displacement $S_{X}$ as $S_{u}=$ $\omega^{2} S_{X}$ yielding $S_{\tau}=\mu \rho \omega^{3} S_{X}$. The variance $\sigma_{\tau}^{2}$ of the shear stress can be calculated as follows:

$$
\sigma_{\tau}^{2}=\int_{0}^{\infty} S_{\tau}(f) \mathrm{df}
$$

Assuming that the amplitudes of the shear stress follow the Rayleigh law, the average value of the amplitude of the oscillating shear stress can be estimated as: $\bar{\tau}_{t}=1.25 \sigma_{\tau}$. For a floating plate oscillating in a steady ambient stream, a rough estimate of the total shear stress can be calculated as a sum of the Blasius and Stokes shear stresses, namely as $\bar{\tau}=\tau_{0}+\bar{\tau}_{t}$. Finally, the ratio $k=1+\bar{\tau}_{\tau} / \tau_{0}$ represents the ratio of the shear stress acting on a floating oscillating plate to that exerted on a fixed plate.

Biological aspects. In order to quantify the number of coral spats on the different modules, settlement plates of all modules were retrieved and examined at 6 and 12 mo post-deployment (March and September 2003, respectively). At those times, 1 horizontal and 1 vertical plate were sampled for each domain of the module, totaling 4 plates per module. Altogether 192 plates were sampled per date: 4 plates per module (2 vertical and 2 horizontal) $\times 3$ modules per installation (seabed, mid and surface) $\times 6$ installations ( 3 fixed and 3 floating) $\times 2$ shallow sites (observatory and north jetty) +4 plates per module ( 2 vertical and 2 horizontal $) \times 2$ modules per installation (seabed and mid) $\times 6$ installations ( 3 fixed and 3 floating) $\times 1$ deep site (south jetty). The removed plates were placed underwater in zip-lock bags and immediately transferred to the IUI laboratory and placed in running seawater until examination. All removed plates were replaced by new ones, in order to maintain the structural features of the modules. Each plate was examined under a dissecting microscope within $24 \mathrm{~h}$ of removal. We recorded the number and size of all stony and soft coral spats on each plate face, as well as on the plate edges, and identified them to the lowest possible taxonomic level. This was followed by biomass measurements for 1 vertical and 1 horizontal plate of the upper domain of each module, totaling 96 plates. All benthic organisms and algae were scraped from the surface of half of the A face of each plate $(11.5 \times 10=$ $115 \mathrm{~cm}^{2}$ ). In order to assess the difference between the plate faces during September 2003, we sampled both faces of each plate of the fixed and floating mid modules at the north jetty. The scraped material was placed in aluminum weighing cups (diameter: $70 \mathrm{~mm}$ ), dried in an oven for $24 \mathrm{~h}\left(60^{\circ} \mathrm{C}\right)$, weighed, burned to ash in a furnace $\left(450^{\circ} \mathrm{C}\right)$ and re-weighed (see Shemla 2001). Subtraction of the ash weight from the dry weight divided by the scraped surface area yielded the organic weight in grams per square centimeter. An additional quarter of the A face of all plates sampled for biomass $(5.75 \times 10$ $=57.5 \mathrm{~cm}^{2}$ ) was scraped for chlorophyll content analy- 
sis. The difference in chlorophyll content between the 2 plate faces was examined similarly to the biomass analyses during September 2003 (see above). The scraped material was filtered with a Whatman, $47 \mathrm{~mm}$ GF/C glass microfiber filter, and the chlorophyll was extracted following the procedure given by Greenberg (1995). The filters were stored in $50 \mathrm{ml}$ plastic vials at $-20^{\circ} \mathrm{C}$ for $2 \mathrm{wk}$, after which 5 to $8 \mathrm{ml}$ of $70 \%$ acetone diluted in filtered seawater $(0.02 \mu \mathrm{m})$ was added to each vial. The samples were then stored at $4{ }^{\circ} \mathrm{C}$ (covered in aluminum foil to prevent deterioration of the chlorophyll) for a $48 \mathrm{~h}$ extraction, after which they were centrifuged twice $(1130 \times g)$ and their chlorophyll a $(\mathrm{chl} a)$ content was measured using a spectrophotometer (Shimadzu, uv-1201). The final chl a content was given in micrograms per square centimeter.

Differences in organic weight, chl a content and coral recruitment between the fixed and floating installations were tested by factorial ANOVA, the factors being: treatment (floating, fixed), module (seabed, mid and surface) and orientation (vertical, horizontal). Stony and soft coral spats were also tested for difference between plate faces (A, B). Differences between plate faces for the biomass and chl a (September 2003) were analyzed using factorial ANOVA, with the factors being: treatment (floating, fixed) and plate face (A, B). We also used factorial ANOVA to test for differences between the 3 sites (observatory, north and south jetties) and between the 2 monitoring dates (6 and $12 \mathrm{mo}$ ) crossed with the treatment (floating, fixed). In order to meet ANOVA assumptions, organic weight and chl a values were log-transformed, and coral spat values were square-root transformed. Data are presented as averaged values per square centimeter for organic weight and chl a con-

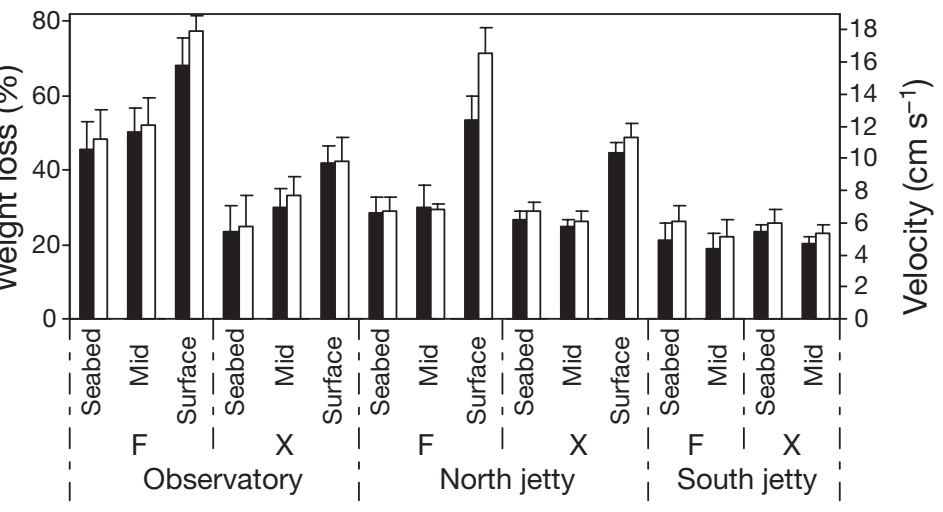

Fig. 4. Estimated current velocity ( $\mathrm{cm} \mathrm{s}^{-1}$, right axis) and weight loss of clod cards (percentage of initial weight, left axis) after $24 \mathrm{~h}$ exposure on the different modules (seabed, mid and surface) of the floating $(F)$ and fixed (X) installations at the 3 study sites; $n=6$ clod cards per treatment (see Table 1 for statistical analyses) (black columns: clod cards positioned at the inner part of the module; white columns: clod cards positioned at the uppermost part of the module)

tent and per plate face for the coral spats. All averaged values are presented with standard deviations.

\section{RESULTS}

\section{Hydrodynamic aspects}

Mass-transfer rate in floating and fixed installations

The clod-card experiments gave the amount of water passing across the settlement plates i.e. mass-transfer rate. As the calibration experiment exhibited a complete linear relation between current velocity and percentage weight loss of the clod cards $\left(r^{2}=0.987\right)$, the resulting calibration curve (Fig. 4) enabled us to link percentage weight loss in the field experiments to current velocity. Mass-transfer rates at the

Table 1. Analysis of clod-card experiments at the 3 study sites, testing for differences in mass-transfer rates between floating and fixed installations, modules within installations (seabed, mid and surface) and different positions within the modules: Face A/B of a settlement plate, vertical/horizontal and inner/upper

(factorial ANOVA: -: not significant; ${ }^{*}: \mathrm{p}<0.05 ;^{* *}: \mathrm{p}<0.01{ }^{* * *}: \mathrm{p}<0.001$ )

\begin{tabular}{|llccc|}
\hline Experiment & Factor & $\begin{array}{c}\text { Obser- } \\
\text { vatory }\end{array}$ & $\begin{array}{c}\text { North } \\
\text { jetty }\end{array}$ & $\begin{array}{c}\text { South } \\
\text { jetty }\end{array}$ \\
\hline I, 27-28 Jul 2003 & Treatment (floating/fixed) & ${ }^{* * *}$ & ${ }^{* *}$ & - \\
& Module (seabed/mid/surface) & ${ }^{* * *}$ & ${ }^{* * *}$ & ${ }^{*}$ \\
& Position (Face A/B) & ${ }^{*}$ & - & - \\
II, 12-13 Aug 2003 & Treatment (floating/fixed) & ${ }^{* * *}$ & ${ }^{* * *}$ & - \\
& Module (seabed/mid/surface) & ${ }^{* * *}$ & ${ }^{* * *}$ & ${ }^{* * *}$ \\
& Position (horizontal/vertical) & - & - & ${ }^{* *}$ \\
III, 26-27 Nov 2003 & Treatment (floating/fixed) & ${ }^{* * *}$ & ${ }^{* * *}$ & - \\
& Module (seabed/mid/surface) & ${ }^{* * *}$ & ${ }^{* * *}$ & ${ }^{* * *}$ \\
& Position (inner/upper) & - & & \\
\hline
\end{tabular}
at the fixed ones at both shallow sites (observatory and north jetty), while no such difference was found at the deep site (south jetty). Current velocities at the floating installations ranged from 11 to $17 \mathrm{~cm} \mathrm{~s}^{-1}$ at the observatory and 7 to $16 \mathrm{~cm} \mathrm{~s}^{-1}$ at the north jetty, while velocities at the fixed installations were much lower (5 to 9 and 5 to $11 \mathrm{~cm} \mathrm{~s}^{-1}$, respectively). Similar velocity patterns were recorded in all experiments (Table 1). Modules at the observatory and north jetty sites showed a distinct gradient of highest mass-transfer rates in the surface modules, with velocities $>18 \mathrm{~cm} \mathrm{~s}^{-1}$, decreasing significantly at 

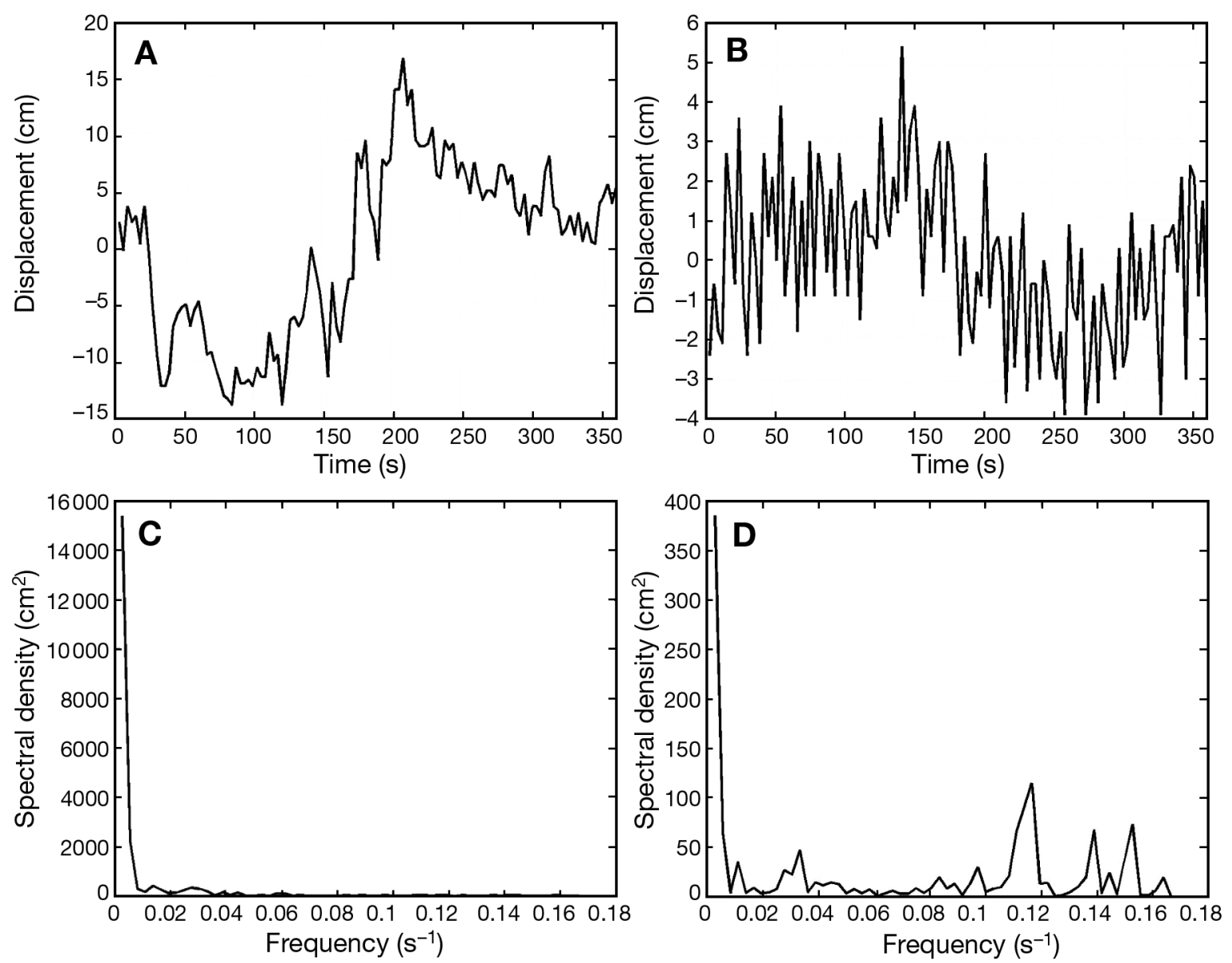

Fig. 5. Displacement (cm) of the floating modules over $360 \mathrm{~s}$ : (A) surface module and (B) mid module. Dominant frequency of the modules, according to standard spectral analysis (spectral density $\mathrm{cm}^{2}$ ): (C) surface module and (D) mid module

the mid and seabed modules, with velocities as low as $4 \mathrm{~cm} \mathrm{~s}^{-1}$. The mass-transfer rate in the different parts of the module varied between sites. Differences between Faces A and B of the uppermost settlement plates were only significant at the observatory, and between vertical and horizontal plates, at the south jetty. Differences between inner and upper positions were found at both the observatory and north jetty (Fig. 4, Table 1). These differences were greatest in the surface module, reaching as high as $5 \mathrm{~cm} \mathrm{~s}^{-1}$ between inner and upper positions at the floating installations of the north jetty (Fig. 4).

\section{Movement frequency of floating installations}

The oscillating movements of the surface and mid modules of the floating installation over a 6 min period are presented in Fig. 5A,B, respectively. The displacement of the seabed modules was similar to that of the mid ones and therefore is not presented. The surface module had the greatest range of displacement (up to
$30 \mathrm{~cm}$ ), while the mid module had a smaller range (up to $10 \mathrm{~cm}$ ). The displacement time series and the spectral densities of the oscillations are presented in Fig. 5C,D. The surface module showed relatively slow motion, with a predominantly low frequency, whereas the mid module oscillated at a high frequency, but with much smaller amplitude. The latter also applied to the seabed module, moving with a slightly higher frequency and smaller amplitude. Apart from this highfrequency motion, the mid and seabed modules also performed low-frequency oscillations, similar to those of the surface module (Fig. 5D). The surface module exhibited an intensive angular motion, with rotation angles of up to $180^{\circ}$ in alternating directions, whereas the mid and seabed ones exhibited minor rotation.

The ratio of the shear stress on floating plates to that on fixed ones was $>1$ (Fig. 6), indicating that the shear stress on floating plates was typically greater than that on fixed ones. The ratio was larger for low current velocities and, consequently, increased for the mid and seabed modules that had encountered rather weak current velocities (Fig. 4). 


\section{Biological aspects}

Organic weight

Average organic weight in terms of grams per square centimeter for each site at both sampling dates is presented in Fig. 7A. At the shallow sites organic weight on the floating installations was higher than on the fixed ones in both March and September 2003, excluding the north jetty in September 2003. On both sampling dates organic weight was higher in the surface module compared to in the mid and seabed ones at the shallow sites, excluding the north jetty in March 2003. A decrease in biomass when approaching the seabed was also found at the south jetty at that time. The effect of plate orientation was also significant there, where the vertical plates had accumulated more organic weight than the horizontal ones. However, in September 2003 this pattern appeared at all sites (Fig. 7A; factorial ANOVA, df $=1$ : $p<0.001$ for the observatory and $p<0.05$ for the north and south jetties). The study sites significantly differed from each other, as the observatory had lower biomass compared to the other 2 sites (Fig. 7A; factorial ANOVA, df $=2: p<0.001)$. Additionally, the amount of biomass significantly differed between March and September 2003 (factorial ANOVA, df = 1: p < 0.001), with the average biomass increasing by 2- to 3 -fold at all sites. Organic weight was higher on Face B compared to Face A at both floating and fixed installations in September 2003 (floating-Face A: $0.410 \pm 0.242$, Face B: $1.075 \pm 0.764$; fixed-Face A: $0.334 \pm 0.198$, Face B: $1.060 \pm 0.798 \mathrm{~g} \mathrm{~cm}^{-2}$; factorial ANOVA, $\mathrm{df}=1$ : $\mathrm{p}<0.005)$.

\section{Chlorophyll content}

Average chl a content in terms of micrograms of chl a per square centimeter was greater at the fixed installations than at the floating ones in March 2003 at both shallow sites (Fig. 7B). This pattern persisted in September 2003 only at the observatory. Differences between the modules were not significant, although an interaction existed between treatment and module position in March 2003 at all sites (Fig. 7B). Fixed installations showed an increase in chl a content towards the surface module, while no such trend appeared in the floating ones. The south jetty showed no difference in chl a content between the floating and fixed installations, but did show higher content in the horizontal plates for both dates. The 3 sites significantly differed from each other, as the south jetty had lower chl a content compared to the other 2 sites (Fig. 7B; factorial ANOVA, df $=2: \mathrm{p}<0.05$ ). The chl $a$

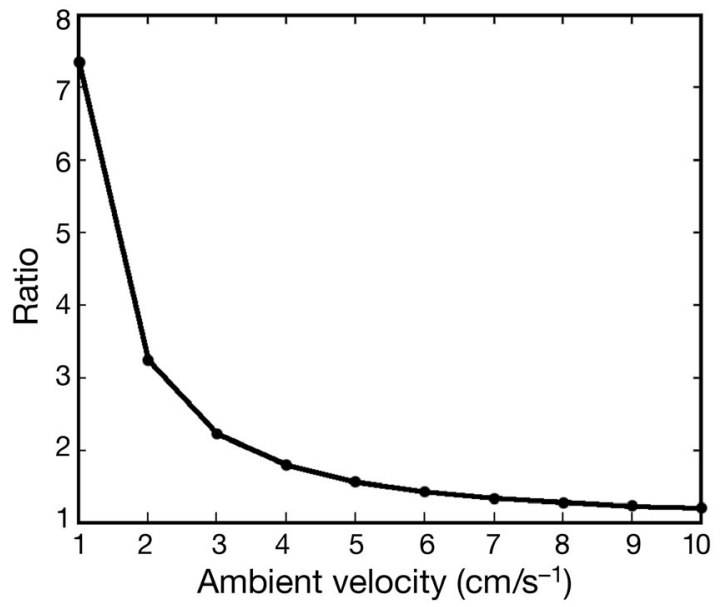

Fig. 6. Ratio of shear stress on the floating oscillating plate to shear stress on the fixed plate, in relation to the ambient flow velocity $\left(\mathrm{cm} \mathrm{s}^{-1}\right)$

content at all sites slightly decreased over time (factorial ANOVA, df = 1: p < 0.001), although the patterns described above were more distinct in March 2003. chl a content was higher on Face A compared to Face B at both floating and fixed installations in September 2003 (floating-Face A: $1.212 \pm 1.288$, Face B: $0.338 \pm 1.292$; fixed-Face A: $0.247 \pm 0.319$, Face B: $0.052 \pm 0.141 \mu \mathrm{g}$ chl $\mathrm{a} \mathrm{cm}^{-2}$; factorial ANOVA, df $=1$ : $\mathrm{p}<0.05$ ).

\section{Coral settlement}

A total of 598 coral recruits appeared on the settlement plates when pooling the March and September examinations, of which 506 were soft corals and only 92 were stony corals. In March 2003, there were no differences in the number of stony corals between floating and fixed installations. Stony corals recruited only to shallow sites, mostly on the seabed module (Fig. 7C). At the observatory, settlement was also affected by orientation, with a high number of stony corals on vertical surfaces. In September 2003, stony coral recruits appeared mostly at the observatory, at the fixed installations (Fig. 7C), and their high recruitment to vertical surfaces persisted. However, the increased recruitment on lower modules was not significant at the 3 sites. The study sites significantly differed from each other, as the observatory had higher coral recruitment of stony corals compared to the other 2 sites (Fig. $7 \mathrm{C}_{i}$ factorial ANOVA, df $=2: \mathrm{p}<0.001$ ). The number of stony coral recruits increased from March to September 2003 (factorial ANOVA; df = 1: p < 0.001), particularly on fixed installations. Differences between the 2 plate faces were not significant on either sampling date; however, in March, an interaction 

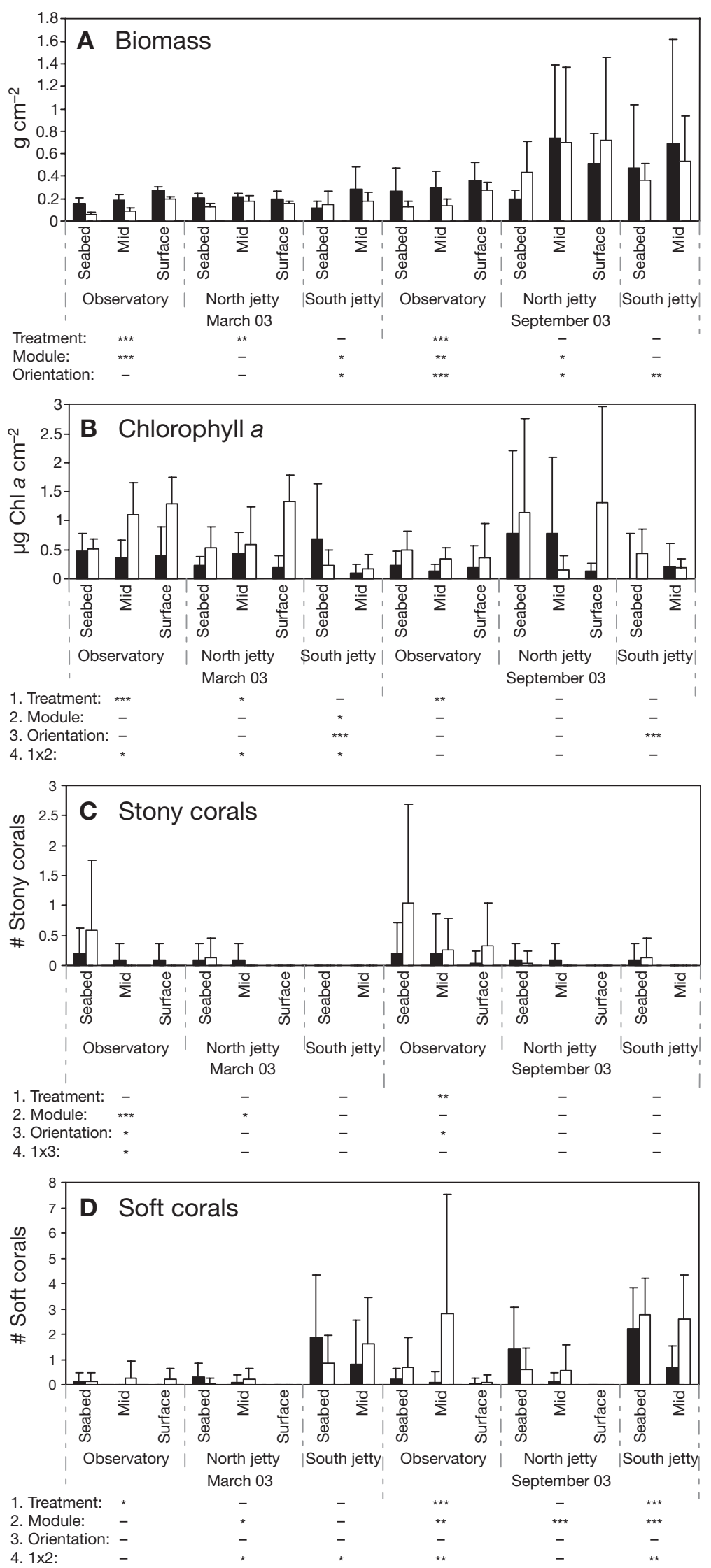

existed between treatment and plate face, as Face B had more stony corals than Face A at the fixed installations, yet not at the floating ones (factorial ANOVA, interaction term: $p<0.05)$. Similarly, an interaction between treatment, module and plate face appeared in September 2003 (factorial ANOVA, interaction term: $\mathrm{p}<0.001$ ).

Soft coral recruits were recorded at all sites on both sampling dates, with no consistent pattern of settlement among sites (Fig. 7D). At the observatory, most soft corals settled on the fixed installations in March 2003, regardless of the position of the module or plate orientation. In September 2003 the preference to settle on fixed installations strengthened at the observatory and south jetty, and differences between modules appeared as most soft corals settled on the seabed and mid modules (Fig. 7D). At the south jetty, most soft corals on floating installations settled on the seabed module, while on the fixed ones they settled mostly on the mid module (Fig. 7D; factorial ANOVA, interaction term: $p<0.05)$. The study sites significantly differed from each other, as the south jetty had higher coral recruitment of soft corals compared to the other 2 sites (Fig. 7D; factorial ANOVA, $\mathrm{df}=2: \mathrm{p}<0.001)$. The number of soft coral recruits significantly increased between March and September 2003 (factorial ANOVA, df $=1: p<0.001$ ), reaching an average of nearly 3 colonies per plate face $\left(116 \mathrm{~cm}^{2}\right)$ at the observatory and south jetty. Differences between the plate faces were not significant on either sampling date; nonetheless, in March, an interaction appeared between treatment and plate face, as more stony corals were found on Face A than on Face B at the fixed installations, yet not at the floating ones (factorial ANOVA, interaction term: $\mathrm{p}<0.01$ ).

Fig. 7. Biological parameters (average $\pm S D, n=6$ ) for seabed, mid water and surface modules of floating (white columns) and fixed (black columns) installations at all sites, in March and September 2003: (A) biomass $\left(\mathrm{g} \mathrm{cm}^{-2}\right)$, (B) chlorophyll content $\left(\mu \mathrm{g} \mathrm{chl} a \mathrm{~cm}^{-2}\right),(\mathrm{C})$ stony coral recruits per plate face and (D) soft coral recruits per plate face. Results of factorial ANOVA for each site and time presented below each graph (-: not significant; ${ }^{*}: \mathrm{p}<0.05_{i}{ }^{* *}: \mathrm{p}<0.01_{i^{* * *}}$ : $\mathrm{p}<0.001)$ 


\section{DISCUSSION}

The results of the study highlight 2 main conclusions regarding benthic communities developing on floating or fixed artificial habitats. First, there are great differences in the hydrodynamic features associated with habitats of different motion capabilities, predominantly in mass-transfer rate, current velocity and shear stress. Second, these hydrodynamic features determine the nature of the benthic communities on floating and fixed habitats. Therefore, our results support the hypothesis of the study that floating artificial habitats are likely to be inhabited by benthic communities different to those of identical fixed habitats.

Current velocity at both shallow sites was greater on floating than on fixed installations (Fig. 4). We can consider the motion of giant kelp in the water column as a natural equivalent to floating installations. The holdfast of the kelp can be compared to the anchor of the floating installations, and their near-surface blades to the buoy. At high current velocities the flexibility of the kelp structure enables it to 'go with the flow' (Denny et al. 1997) and thus reduce the hydrodynamic forces imposed on it (Hurd 2000). At lower velocities, where nutrient flux can be a limiting factor, kelp blades reorientate in relation to the current, thus increasing the mass-transfer rate and elevating the flux to the blades (Denny \& Roberson 2002). Although the floating installations had 6 degrees of freedom, their movement was dictated by the wave, wind and tidal action affecting the motion of the buoy and, consequently, the whole installation, particularly the surface module positioned directly below the buoy. We suggest that this movement greatly increases the mass-transfer rate on the floating installations compared to fixed ones, similar to the increase in the mass-transfer rate on kelp in motion. Analyses of the movement frequencies revealed that the motion of the surface module had a low movement frequency with a large amplitude (Fig. 5A,C), acting almost as a harmonic movement similar to wave action, while the mid and seabed modules had a smaller amplitude with a high frequency (Fig. 5B,D), reflecting the natural frequency of the installation. Therefore, we conclude that the motion of the floating installation, rather than reducing the current velocities felt on its surface area, increases it, elevating the shear stress on the settlement plates compared to that of the fixed installations.

Current regime strongly affected community development on the fixed and floating installations. In our study floating installations at the shallow sites had greater biomass, less chl a content and less coral recruitment compared to fixed ones (Fig. 7). It would thus seem that floating installations, exposed to high mass-transfer rates and current velocities, encourage massive settlement of benthic macroinvertebrates such as ascidians, bryozoans, sponges, polychaetes and bivalves, which made a significant contribution to the total biomass (Perkol-Finkel et al. unpubl. data), while fixed installations had a higher proportion of algae and corals. Fairfull \& Harriott (1999) similarly found a negative relation between the appearance of benthic macroinvertebrates, and the distribution of corals and algae in subtropical communities. They demonstrated high abundance of the above-mentioned taxa on the lower surface of settlement plates and greater algal cover and coral settlement on the upper surface, resulting from the strong competitive abilities of other benthic invertebrates. While this may also apply to our study, we suggest that the current regime accounts for the difference found in community structure between floating and fixed installations. As current velocity and mass-transfer rate are associated with food transport and nutrient supply, they are of great importance for filter feeders (Shimeta \& Jumars 1991, Abelson \& Denny 1997), which dominated the floating installations. The highest biomass at both types of installations was found at the surface module (Fig. 7A), where mass-transfer rates were greatest (Fig. 4), particularly at the floating installations. Since factors such as orientation, shading and sedimentation levels are similar at the floating and fixed installations, we suggest that current regime is the main factor differentiating biomass values between the 2 types.

Coral recruits were mostly found at the fixed installations, mainly at the seabed and mid modules (Fig. 7C,D), where current velocities were lowest (Fig. 4). Current velocity, shear stress and small-scale current regime strongly affect coral settlement (Abelson 1997, Qian et al. 2000, Harri \& Kayanne 2002). According to Abelson \& Denny (1997), flow can affect settlement at 3 levels: (1) in determining larval encounter with the substratum and their ensuing behavior, (2) in providing a settlement cue and (3) in mediating other cues such as sediment load and concentration of attractants. As a result, certain coral species settle at low current velocities, while others settle at higher ones, or in a wide range of current regimes (Harii \& Kayanne 2002). Thus, preferential settlement may account for differences in coral recruitment on floating and fixed installations, affected by the lower shear stress on the surface of motionless plates compared to that on those oscillating in the ambient flow, particularly at lower current velocities near the seabed (Fig. 4). Since shear stress and current velocity also affect the settlement (Qian et al. 2000) and feeding (Eckman et al. 1989, Patterson 1991, Sebens \& Johnson 1991) of other benthic invertebrates, they can explain the observed differences in biomass between the floating and fixed 
installations, as well as differences between biomass on the seabed, mid and surface modules.

Current regime is not the only factor to be considered in regard to the differentiating fauna of floating and fixed installations. Sediment load is known to be affected by motion of the substratum and may influence benthic communities as some species are more tolerant to this factor than others. For example, certain soft corals withstand sediment better than stony corals (Riegl 1995). This may explain our finding that stony corals exhibited preference for vertical surfaces (Fig. 7C, observatory), while soft corals were indifferent to orientation (Fig. 7D). It is expected that sediment load will be greatest near the seabed, particularly on fixed installations that tend to accumulate sediment. However, no indication of significant differences in sedimentation load was found between the 2 types of installations at the shallow sites (work in progress). Interaction between nearby organisms and the installations may also affect community composition. For example, extensions of encrusting species, as well as asexually produced propagules by species such as Dendronephthya hemprichi (Dahan \& Benayahu 1997), Scleronephthya corymbosa (Lutzky 1997) and Ovabunda macrospiculata (Benayahu \& Loya 1985), can expand to the settlement plates. Nonetheless, we did not observe direct overgrowth at the fixed installations, due to the presence of the metal bands (Fig. 2). Moreover, both sexual and asexual propagules can equally reach modules of the fixed and floating installations, as supported by the results from the south jetty. At this deep site hardly any differences in biological parameters were observed (Fig. 7), despite the presence of nearby organisms on the pillars that held the fixed installations. Additionally, mass-transfer rate did not differentiate between floating and fixed installations (Table 1), presumably due to low current velocities compared to the shallow sites (Fig. 4). Furthermore, it is possible that fixed installations may be exposed to higher predation pressure compared to floating ones, due to their direct association with the seabed. However, floating installations were exposed to pelagic predators (Halperin 2004), as well as to benthic ones, which were observed crawling on the cables anchoring the floating modules to the seabed. Additionally, Holloway \& Connell (2002), who studied fouling communities on floating versus fixed artificial habitats, found that connectivity to the benthos was unimportant in determining their community structure, while motion capabilities and hydrodynamics were significant. Therefore, we suggest that our results demonstrate the genuine effects of substratum motion and its associated current regime on the developing benthic communities.
In conclusion, the present study reveals a link between the current velocities, mass-transfer rate and shear stress that are dictated by the motion ability of the substratum and the biological features of a benthic community. We successfully applied simple methods for measuring small-scale currents, which can be applied in future studies of coastal artificial habitats. The obtained results may allow prediction of the composition of benthic assemblages on floating and fixed artificial habitats in reefal environments. The study contributes to a better understanding of why urbanization of coastal zones in tropical systems generates unique species assemblages of sessile organisms.

Acknowledgements. We thank the Interuniversity Institute of Eilat for assistance and use of facilities. We thank the EilatAshqelon Pipe Line Company (EAPC) and Eilat Underwater Observatory for allowing the research at their premises. We appreciate the helpful comments of the anonymous reviewers, which greatly improved the quality of the manuscript. Special thanks to O. Ben-Shaprut for skillful field assistance. We thank N. Paz for editorial assistance and V. Wexsler for graphic assistance. We acknowledge the Israeli Nature and National Park Protection Authority for cooperation. The study was supported by a grant from The Porter School of Environmental Studies (PSES) at Tel Aviv University and in part by The Tobias Landau Foundation.

\section{LITERATURE CITED}

Abelson A (1997) Settlement in flow: upstream exploration of substrata by weakly swimming larvae. Ecology 78:160-166

Abelson A, Denny M (1997) Settlement of marine organisms in flow. Annu Rev Ecol Syst 28:317-339

Abelson A, Weihs D, Loya Y (1994) Hydrodynamic impediments to settlement of marine propagules, and adhesivefilament solutions. Limnol Oceanogr 39:164-169

Baine M (2001) Artificial reefs: a review of their design, application, management and performance. Ocean Coast Manage 44:241-259

Baird ME, Atkinson MJ (1997) Measurement and prediction of mass transfer to experimental coral reef communities. Limnol Oceanogr 42:1685-1693

Bellan GL, Bellan-Santini DR (2001) A review of littoral tourism, sport and leisure activities: consequences on marine flora and fauna. Aquat Conserv 11:325-333

Benayahu Y, Loya Y (1985) Settlement and recruitment of a soft coral: Why is Xenia macrospiculata a successful colonizer? Bull Mar Sci 36:177-188

Bendat JS, Piersol AG (1980) Engineering application of correlation and spectral analysis. John Wiley \& Sons, New York

Ben-David-Zaslow R, Benayahu Y (1998) Competence and longevity in planulae of several species of soft corals. Mar Ecol Prog Ser 163:235-243

Boxshall AJ (2000) The importance of flow and settlement cues to larvae of the abalone, Haliotis rufescens Swainson. J Exp Mar Biol Ecol 254:143-167

Chapman MG, Bulleri F (2003) Intertidal seawalls - new features of landscape in intertidal environments. Landsc Urban Plann 62:159-172 
Chou LM, Lim TM (1986) A preliminary study of the coral community on artificial and natural substrates. Malay Nat J 39:225-229

Connell SD (2000) Floating pontoons create novel habitats for subtidal epibiota. J Exp Mar Biol Ecol 247:183-194

Connell SD, Glasby TM (1999) Do urban structures influence local abundance and diversity of subtidal epibiota? A case study from Sydney harbour Australia. Mar Environ Res 47: 373-387

Dahan M, Benayahu Y (1997) Clonal propagation by the azooxanthellate octocoral Dendronephthya hemprichi. Coral Reefs 16:5-12

Denny MW, Roberson L (2002) Blade motion and nutrient flux to the kelp Eisenia arborea. Biol Bull (Woods Hole) 203: 1-13

Denny MW, Gaylord BP, Cowen BA (1997) Flow and flexibility. II. The roles of size and shape in determining wave forces on the bull kelp Nereocystis luetkeana. J Exp Biol 200:3165-3183

Doty MS (1971) Measurements of water movement in reference to benthic algal growth. Bot Mar 14:32-35

Eckman JE, Duggins DO (1998) Larval settlement in turbulent pipe flows. J Mar Res 56:1285-1312

Eckman JE, Duggins DO, Sewell AT (1989) Ecology of understory kelp environments. 1. Effects of kelps on flow and particle-transport near the bottom. J Exp Mar Biol Ecol 129:173-187

Eckman JE, Werner FE, Gross TF (1994) Modeling some effects of behavior on larval settlement in a turbulent boundary layer. Deep-Sea Res II 41:185-208

Fairfull SJL, Harriott VJ (1999) Succession, space and coral recruitment in a subtropical fouling community. Mar Freshw Res 50:235-242

Fonseca DM (1999) Fluid-mediated dispersal in streams: models of settlement from the drift. Oecologia 121: 212-223

Glasby TM (1999) Interactive effects of shading and proximity to the seafloor on the development of subtidal epibiotic assemblages. Mar Ecol Prog Ser 190:113-124

Glasby TM (2001) Development of sessile marine assemblages on fixed versus moving substrata. Mar Ecol Prog Ser 215:37-47

Glasby TM, Connell SD (2001) Orientation and position of substrata have large effects on epibiotic assemblages. Mar Ecol Prog Ser 214:127-135

Greenberg AE (1995) Standard methods for the examination of water and wastewater, 19th edn. APHA, Washington, DC

Gross TF, Werner FE, Eckman JE (1992) Numerical modeling of larval settlement in turbulent bottom boundary-layers. J Mar Res 50:611-642

Halperin M (2004) Dynamics of the fish community on fixed and floating artificial reefs in the northern Gulf of Eilat (Red Sea). MSc thesis, Tel Aviv University (In Hebrew, English summary)

Harii S, Kayanne H (2002) Larval settlement of corals in flowing water using a racetrack flume. Mar Technol Soc J 36 $76-79$

Holloway MG, Connell SD (2002) Why do floating structures create novel habitats for subtidal epibiota? Mar Ecol Prog Ser 235:43-52

Hurd CL (2000) Water motion, marine macroalgal physiology, and production. J Phycol 36:453-472

IPCC (Intergovernmental Panel on Climate Change) (1994) Preparing to meet the coastal challenges of the 21st century: conference report of the World Coast Conference 1993. Ministry of Transport, Public Works and Water Management, Government of the Netherlands, The Hague
Kiflawi M, Genin A (1997) Prey flux manipulation and the feeding rates of reef-dwelling planktivorous fish. Ecology 78:1062-1077

Kraines SB, Yanagi T, Isobe M, Komiyama H (1998) Windwave driven circulation on the coral reef at Bora Bay, Miyako Island. Coral Reefs 17:133-143

Lutzky S (1997) Reproductive strategies of two soft coral species: Scleronephthya corymbosa and Nephthea sp. MSc thesis, Tel Aviv University (In Hebrew, English summary)

McDonnell MJ, Pickett STA (1990) Ecosystem structure and function along urban-rural gradients: an unexploited opportunity for ecology. Ecology 71:1232-1237

Oren U, Benayahu Y (1997) Transplantation of juvenile corals: a new approach for enhancing colonization of artificial reefs. Mar Biol 127:499-505

Patterson MR (1991) The effects of flow on polyp-level prey capture in an octocoral, Alcyonium sederium. Biol Bull (Woods Hole) 180:93-102

Perkol-Finkel S, Benayahu Y (2004) Community structure of stony and soft corals on vertical unplanned artificial reefs in Eilat (Red Sea): comparison to natural reefs. Coral Reefs 23:195-205

Qian PY, Rittschof D, Sreedhar B (2000) Macrofouling in unidirectional flow: miniature pipes as experimental models for studying the interaction of flow and surface characteristics on the attachment of barnacle, bryozoan and polychaete larvae. Mar Ecol Prog Ser 207:109-121

Qiu JW, Thiyagarajan V, Leung AWY, Qian PY (2003) Development of a marine subtidal epibiotic community in Kong-Kong: implications for deployment of artificial reefs. Biofouling 19:37-46

Riegl B (1995) Effects of sand deposition on scleractinian and alcyonacean corals. Mar Biol 121:517-526

Roberts CM, Hawkins JP (1999) Extinction risk in the sea. Trends Ecol Evol 14:241-246

Schlichting H (1979) Boundary-layer theory, 7th edn. McGraw-Hill, New York

Seaman W (2002) Unifying trends and opportunities in global artificial reef research, including evaluation. ICES J Mar Sci 59(Suppl):14-16

Sebens KP, Johnson AS (1991) Effects of water movement on prey capture and distribution of reef corals. Hydrobiologia 226:91-101

Sebens KP, Grace SP, Helmuth B, Maney EJ Jr, Miles JS (1998) Water flow and prey capture by three scleractinian corals, Madracis mirabilis, Montastrea cavernosaand, Porites porites, in a field enclosure. Mar Biol 131:347-360

Shemla A (2001) Environmental factors that are shaping artificial reef communities. MSc thesis, Tel Aviv University (In Hebrew, English summary)

Sheng YP (2000) Physical characteristics and engineering at reef sites. In: Seaman W (ed) Artificial reef evaluation with application to natural marine habitats. CRC Press, Boca Raton, p 51-94

Shimeta J, Jumars PA (1991) Physical mechanisms and rates of particle capture by suspension-feeders. Oceanogr Mar Biol Annu Rev 29:191-257

Svane IB, Petersen JK (2001) On the problems of epibiosis, fouling and artificial reefs, a review. PSZN I: Mar Ecol 33: 169-188

Thompson TL, Glenn EP (1994) Plaster standards to measure water motion. Limnol Oceanogr 39:1768-1779

Wethey DS (1986) Ranking of settlement cues by barnacle larvae: influence of surface contour. Bull Mar Sci 39:393-400

Wilding TA, Sayer MDJ (2002) Evaluating artificial reef performance: approaches to pre- and post-deployment research. ICES J Mar Sci 59(Suppl):222-230 